\title{
New Age Audit Assessment Approach for Older Workers in a Longevity Economy: Ways to Support Their Positive Health Outcomes and Career Work-life Extension Efforts
}

\author{
Lisa Hollis-Sawyer, Ph.D.
}

Northeastern Illinois University, Chicago, IL. l-hollissawyer@neiu.edu

*Corresponding Author: Lisa Hollis-Sawyer, Ph.D. Northeastern Illinois University, Chicago, IL.

\begin{abstract}
Increasingly, aging adults will be wanting to "age in place" in their homes, workplaces, healthcare services, and broader living communities (e.g., Alley, Liebig, Pynoos, Banerjee, \& Choi, 2007; WHO, 2015). To date, no one has developed a holistic "age audit" tool to evaluate the age friendliness of the workplace. Age friendliness in workplace environments goes beyond being a safe and physically-accommodating (e.g., accessible) environment, they also need to support aging workers through reducing the likelihood of loneliness and isolation, fostering cultural diversity in decision making, educating about healthy lifestyle practices, and increasing physical, social, and cognitive engagement. Based upon the content review of available age audit tools, it was concluded that most assessments focus on one aspect of older adult functioning in isolation (e.g., psychomotor capability), the age audit tools are limited in user options and limited in functionality for daily assessments, most age audit tools assessments focus on decline and limitations in older adult's functioning, and to understand personenvironment "fit" issues, employers need to design multi-sensory, multi-function assessments reflecting an integrated and coordinated system of sensory, psychomotor, social, and cognitive performance. A conceptual model related to the design of a workplace-based age audit tool is presented for assessment purposes.
\end{abstract}

\section{INTRODUCTION}

By the year 2020, older Americans are projected to be about $20 \%$ of the population (Ortma, Velkoff, \& Hogan, 2015; Scharlach, 2011). Increasingly, aging adults (e.g., Baby Boomers) will be wanting to "age in place" in their homes, workplaces, healthcare services, and broader living communities (e.g., Alley, Liebig, Pynoos, Banerjee, \& Choi, 2007). This trend is a reflection of the current and projected aging trends on a global basis (e.g., WHO, 2015).

Despite this rapidly growing segment of the U.S. and global population (e.g., Menec, et al., 2011), to date, no one has developed an "age audit" tool to evaluate the age friendliness of workplace and living environments to facilitate older adults' positive mental/cognitive health, physical health, social/interpersonal health, and general aging adaptation. Age friendliness in workplace environments goes beyond being a safe and physically-accommodating (e.g., physically accessible) environment, they also need to support aging clients through (1) reducing the likelihood of loneliness and isolation, (2) fostering cultural diversity in care decision making, (3) educating about healthy lifestyle practices, and (4)increasing both physical and cognitive engagement.

Why is this important to understand? Much of the past research on this topic over the last 35 years or so suggest that there is a meaningful correspondence between one's perceptions of the workplace ("fit") and one's general feelings of life satisfaction, or quality of life, across the life span into later life (Butt \& Beiser, 1987; Fillenbaum, 1971; Forteza \& Prieto, 1994; Louhevaara, Penttinen, \& Tuomi, 1999; Lund \& Borg, 1999; Palmore, 1969; Seitsamo \& Martikainen, 
New Age Audit Assessment Approach for Older Workers in a Longevity Economy: Ways to Support Their Positive Health Outcomes and Career Work-life Extension Efforts

1999). More recent research, however, is strongly suggesting that work satisfaction and associated work attitudes is a complex reaction, encompassing both contextual factors of the workplace/organization and individualistic factors of the aging worker (i.e., needs, motivations, and perceptions) (Hedge, Borman, \& Lammlein, 2006; Kiyonaga, 2004; Leibold, et al., 2007; Oromanen, 2006; Wright, 2006). This knowledge is especially crucial under dual conditions of a growing aging workforce (e.g., Baby Boomers) and increasingly normative organizational change in the workplace (e.g., Farr, Tesluk, \& Klein, 1998; Kidwell, 2003; Leibold, et al., 2007).

The assessment of workers' attitudes should examine many different specific aspects of the organization, not just general feelings of job satisfaction. Recent research suggests that older workers' increasingly raise concerns about lack of managerial support toward career work-life extension, associated training opportunities, fairness in management policies/practices (e.g., perceived age biases, age discrimination), and financial security (e.g., pension system solvency) (e.g., Hedge et al., 2006; Noonan, 2005). If specific perceived organizational "barriers" are not determined and addressed, the goal of having a productive, healthy workforce for all age groups involved will be undermined (Gray \& McGregor, 2003; Griffiths, 1999; Hedge et al., 2006; Leibold, et al., 2007).

The present study did an exhaustive review of available age-audit resources and tools related to the assessment of working environments. The present research reviewed published age audit instruments $(n=8)$, associated publications $(n=2$ books and 9 articles/reports/manuals), and three training videos to guide the design of a new App tool for use with phones or tablets with hard copy form also to be utilized by both employers and older workers to assess the age friendliness of workplaces for intervention purposes. An independent rater trained in the process of content review but unaware of the study's purpose was utilized.

\section{MATERIALS}

The researcher collected the following Age Audit Approaches/Tools for the review process (sample):
Acas Age Audit Tool (http://www.acas.org.uk/), LGBT Age Audit Tool (http://www.lgbthealth.org.uk/), Age Friendly Communities Audit Tool (http://www. wheatbelt.wa.gov.au/), Age Equality Audit Tool (http:// age-equality. southwest.nhs.uk/), and Microscale Audit of Pedestrian Streetscapes (http://www.cdc.gov/Pcd/ issues/2015/15_0098.htm).

In addition to the collection of available age audit tools/ approaches, the researcher collectedthe following books, reports, and manuals for the review process (sample): Acas Age Audit Tool User Guide (http://www. acas.org.uk/ media/pdf/2/o/Acas-Age-Audit-ToolUser-Guide.pdf), The Age Audit: Delivering a Business Response to Ageing (2014)(UK aging population; http://www.ilcuk.org.uk/), Age Audit 2015 (2015) (UK National Pensioners' Convention; http://npcuk. org/1982), Village Life (2015) (http://www.ilcuk.org. uk/), and Opportunity Knocks: Designing Solutions for an Ageing Society (2015) (http://www.ilcuk.org.uk/).

\section{PRocedure}

The researcher, in parallel with the independent rater, conducted a content analysis of the different available age audit tools and informational resources to identify: (1) current practices in age audit assessments (e.g., "user friendliness" of audit tools for practitioners), (2) potential biases/limitations in age audit assessments (e.g., "decline/decrement" aging perspective), and (3) "gaps" in assessments to create a more holistic assessment tool. After the content ratings were complete, a meeting to compare the results was done and the inter-rater reliability in content agreement was 87.

\section{RESUlts}

Based upon the content review related to assessing adult-environment "fit," the following conclusions were made. The information from these insights led to the development of both the assessment levels and dimensions (see Tables 1 and 2) as well as the theoretical ideas underlying a multidimensional, multi-outcomes tool for the assessment of workplaces to best support qualified aging workers' career worklife extension efforts (see Figures 1 and 2). 
New Age Audit Assessment Approach for Older Workers in a Longevity Economy: Ways to Support Their Positive Health Outcomes and Career Work-life Extension Efforts

Table 1. "Positive Aging" Age Audit Tool Template for the Design of an App and Hard Copy Format

\begin{tabular}{|c|c|c|c|c|}
\hline \multicolumn{5}{|c|}{ Workplace Environment Assessment Dimensions } \\
\hline Physical & Psychological & Social/Cultural & Cognitive & $\begin{array}{l}\text { Adaptive/Responsive } \\
\text { (Diversity) }\end{array}$ \\
\hline \multicolumn{5}{|c|}{ Age Friendliness Age Audit Assessment Scale } \\
\hline $\begin{array}{l}\text { Very Age } \\
\text { Unfriendly }\end{array}$ & $\begin{array}{l}\text { Somewhat } \\
\text { Age Unfriendly }\end{array}$ & Age Neutral & $\begin{array}{l}\text { Somewhat } \\
\text { Age Friendly }\end{array}$ & $\begin{array}{l}\text { Very Age } \\
\text { Friendly }\end{array}$ \\
\hline $\begin{array}{l}1 \\
\text { (factor-specific } \\
\text { keywords to input } \\
\text { for sub score } \\
\text { calculation) }\end{array}$ & $\begin{array}{l}2 \\
\text { (factor-specific } \\
\text { keywords to input } \\
\text { for sub score } \\
\text { calculation) }\end{array}$ & $\begin{array}{l}3 \\
\text { (factor-specific } \\
\text { keywords to input } \\
\text { for sub score } \\
\text { calculation) }\end{array}$ & $\begin{array}{l}4 \\
\text { (factor-specific } \\
\text { keywords to input } \\
\text { for sub score } \\
\text { calculation) }\end{array}$ & $\begin{array}{l}5 \\
\text { (factor-specific } \\
\text { keywords to input } \\
\text { for sub score } \\
\text { calculation) }\end{array}$ \\
\hline
\end{tabular}

Table 2. Example "Physical Dimension" Assessment Items in Age Audit Tool

\begin{tabular}{|l|}
\hline Vision/Lighting: \\
\hline - glare from indirect illumination on vertical surfaces \\
- seating area just inside entranceways for vision adjustment \\
\hline Hearing/Sound/Noise: \\
\hline - background ambient noise at a minimum \\
- acoustic ceiling/wall products used \\
\hline Mobility (e.g., doors): \\
\hline - width: clearance of wheelchair \\
- maximum force to open/close: 8 lbs pull; 14 lbs push \\
\hline Floors: \\
\hline - carpeting: low pile \\
- contrast between floor and baseboard \\
\hline Furniture (e.g., tables): \\
\hline - table edges have contrasting color border \\
\hline Furniture (e.g., chairs): \\
\hline - chair legs able to be fit with blocks to further raise seat height \\
\hline
\end{tabular}

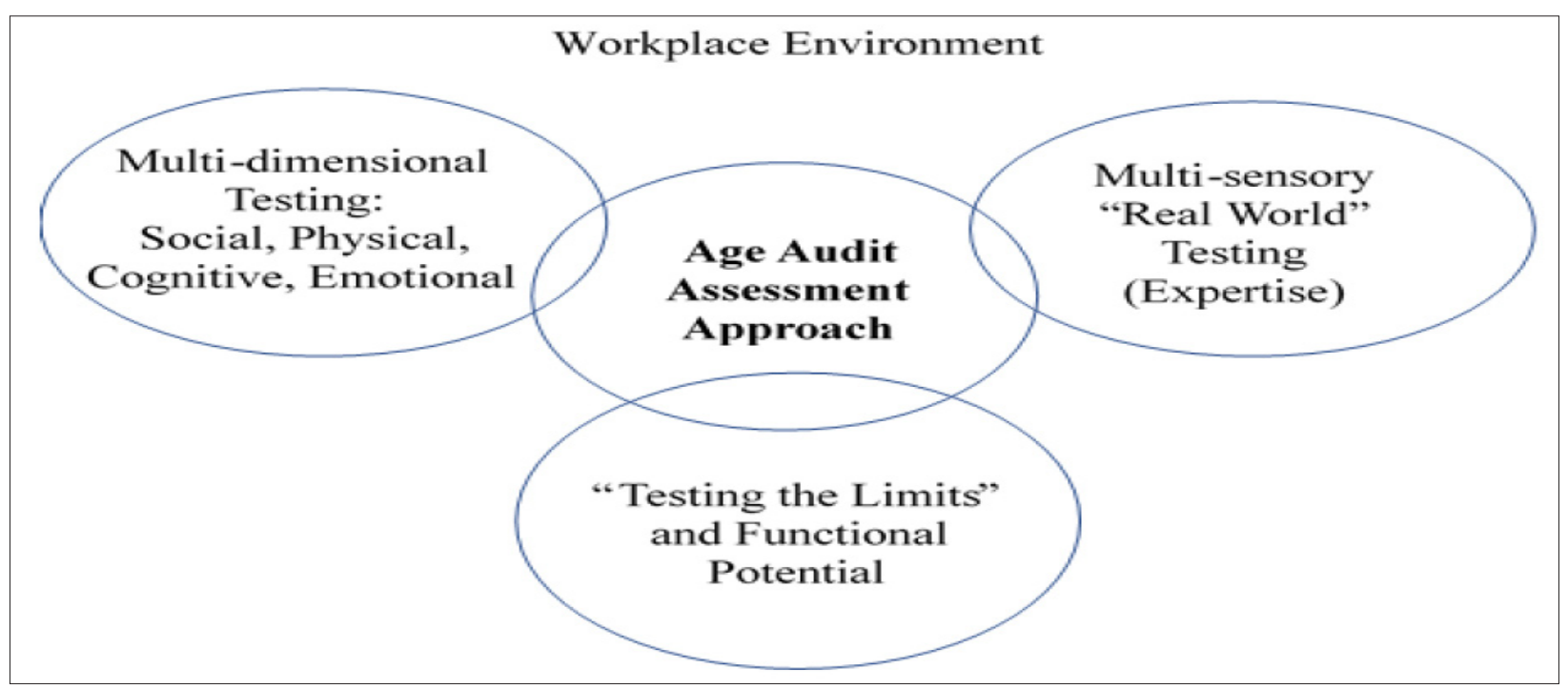

Figure 1. "Positive Aging" Age Audit Assessment Model 
New Age Audit Assessment Approach for Older Workers in a Longevity Economy: Ways to Support Their Positive Health Outcomes and Career Work-life Extension Efforts

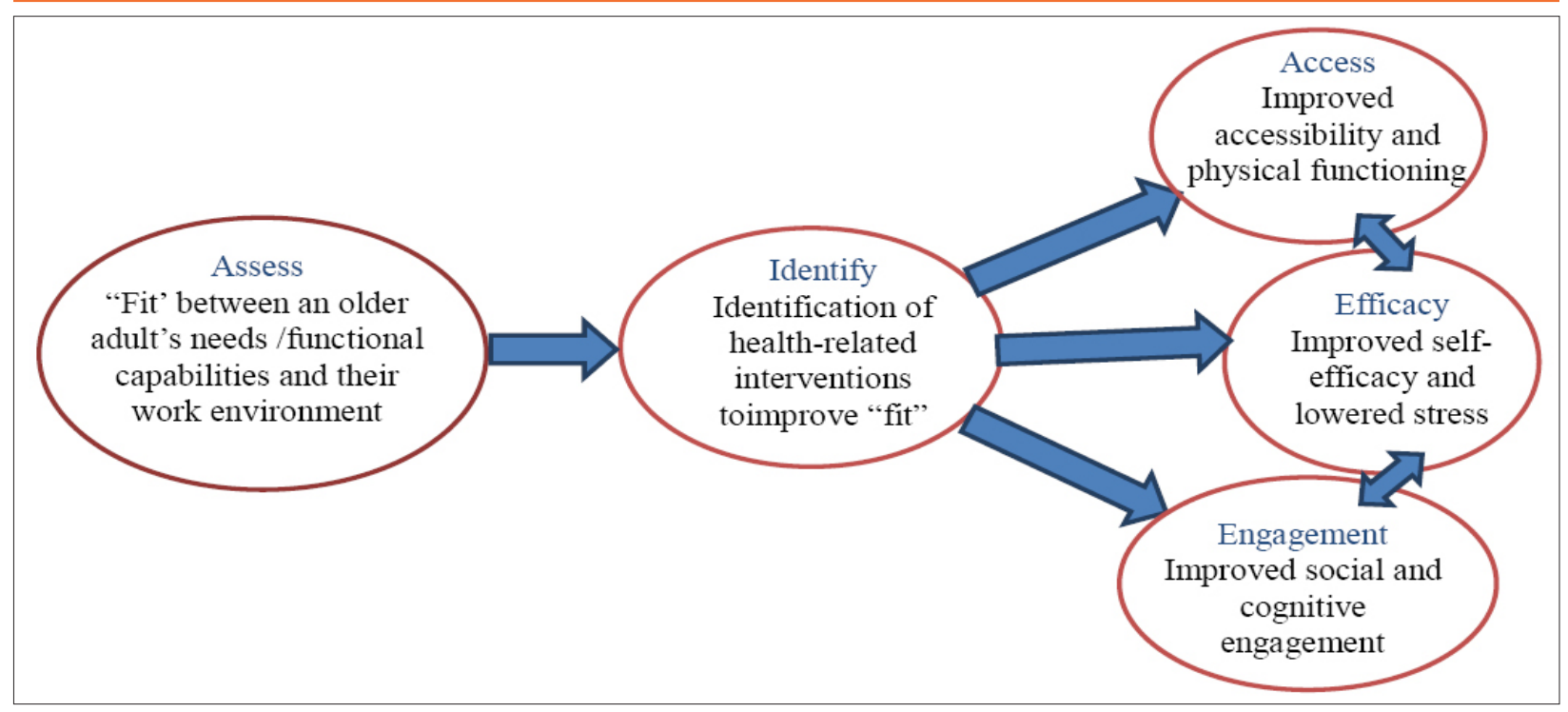

Figure 2. Linkage Model of an Assessment of "Age Friendliness" in the Workplace to Support a Longevity Economy

The first finding from the content review process was that most assessments focus on one aspect of older adult functioning in isolation (e.g., psychomotor). There is a need for a more "holistic" age audit tools that assesses older adults' normative physical, social, emotional, and cognitive functioning. In application, a more comprehensive design in age audit tools is needed to effectively identify multi-dimensional "aging in place" issues to be addressed and/or interventions to assist in supporting their quality of life needs.

The second content finding was that most age audit tools assessments focus on decline and limitations in older adult's functioning. Age audit assessment approaches should focus on assessing the potential learning and modifiability of older adults' cognitive, social, emotional and physical functioning from a "testing the limits" approach in conjunction with living environment interventions. This exemplifies a laterlife plasticity perspective in design. In application, a more extensive age audit tool that identifies older adults' functioning potential in functioning is needed as people are living longer than ever before and wish to remain independent with the help of "age friendly" design.

Last, the findings suggest that, to understand "fit" issues, it would be most helpful to design multi-sensory assessments reflecting an integrated and coordinated system of sensory, psychomotor, and cognitive performance strategies learned over a life span (e.g., Baltes' selective optimization with compensation). Develop age audit tools that assess "real world" tasks that would reflect activities of daily living and/or in the workplace. In application, an age audit tool that better identifies older adult's everyday functioning potential will assist in creating better "fit" in design between an adult and his/her environment (e.g., home, work, and/or educational settings).

\section{Discussion}

As the mean age of the U.S. and general World population continues to rise, the need to support career work-life extension for qualified, competent aging Baby Boomers will become a societal concern for all involved (e.g., employers, aging employees, their families/dependents), and the needs of this large working sub-populations need to be acknowledged as having potentially unique issues related to both aging and non-aging factors (e.g. cohort membership). The present findings suggest that it cannot be assumed that all aging workers are equally positive, or receptive, to specific organizational policies and or practices (e.g., ethical practices) (Hedge, et al., 2006; Leipold, et al., 2007).

Based upon the content review related to assessing adult-environment "fit," the following conclusions were made: (1) most assessments focus on one 
New Age Audit Assessment Approach for Older Workers in a Longevity Economy: Ways to Support Their Positive Health Outcomes and Career Work-life Extension Efforts

aspect of older adult functioning in isolation (e.g., psychomotor capability), (2) the age audit tools are limited in user options and limited in functionality for daily assessments, (3) most age audit tools assessments focus on decline and limitations in older adult's functioning, and (4) to understand personenvironment "fit" issues, employers need to design multi-sensory, multi-function assessments reflecting an integrated and coordinated system of sensory, psychomotor, social, and cognitive performance.

An increasing reality for aging Baby Boomers is the need to remain in the workforce past "traditional" retirement age for both necessity and/or motivational reasons (e.g., maintaining one's work role as a "quality of life" concern). Understanding changing job attitudes and reactions over time are important to understand in the workplace, both as employers and as aging employers ourselves, especially under increasingly normative conditions of organizational change (Farr et al., 1998).

A life-span perspective in long-term career planning to better support career work life extension is for all cohorts, present and future, regardless of individualdifference characteristics.

The "key" is to continually update one's knowledge about an aging workforce to ensure these efforts are effective! Job reactions are a multi-dimensional, complex, and important source of information for both employers and employees of all ages. The issues raised by the present study are not only for older workers, but relate to all workers across the life span. All cohorts will experience "aging" in the workplace, and this cohort by aging dynamic does need to be acknowledged rather than assumed to be universal for all age groups. Further, organizational assessment needs to go beyond the age by job satisfaction relationship to more specific workplace issues, as well as factors of gender role and culture as it affects job reactions. Ultimately, if not better understood, there may be a likely increase in qualified, capable older workers exiting the workforce involuntarily (i.e., "discouraged workers"), and potentially creating "gaps" in job positions that may not be replaceable in full.

\section{CONCLUSION}

An optimized person-environment "fit" in a workplace environment can assist in older adults' maintenance of their physical health (e.g., activity level), cognitive health (e.g., mental "aerobics"), social health (e.g., social engagement), and mental health (e.g., positive aging adaptation). How age, cohort membership, and these other individual-difference factors interact (e.g., gender role expectations) needs further investigation in complex terms for analysis and workplace intervention purposes. "Career work-life extension" is and will be a desire, if not a necessity, for a growing "gray" workforce and its employers needing positions to remain filled by experienced workers; the key to achieving this goal is to better understand the impact of many factors, not just age alone, on older workers' reactions to the workplace and their jobs. Once this is understood only then can appropriate workplace interventions be implemented to sustain a motivated, qualified aging workforce in society.

An increasing reality for aging Baby Boomers is the need to remain in the workforce past "traditional" retirement age for both necessity and/or motivational reasons (e.g., maintaining one's work role as a "quality of life" concern). Understanding changing job attitudes andreactions over time are important to understand in the workplace, both as employers and as aging employers ourselves, especially under increasingly normative conditions of organizational change (Farr et al., 1998).

Why are improved "age friendly" environments needed?"Age friendly" environments not only need to be safe and physically accommodating, like disability friendly environments, they also need tolimit the potential for loneliness and isolation, foster creativity and cultural diversity, assist in healthy lifestyles, and maintain continuity of identity across the life span (e.g., Leipert, Garcia, \& Kloseck, 2011; World Health Organization (WHO), 2013). From an Activity Theory agingperspective (Havighurst, 1961), educators and practitioners need to re-examine issues of environment accessibility and support affecting the "aging in place" opportunities for a growing aging global society. Older adults will be living longer and healthier than previous 
New Age Audit Assessment Approach for Older Workers in a Longevity Economy: Ways to Support Their Positive Health Outcomes and Career Work-life Extension Efforts

cohorts, and their need to be active and contributing members within society are of benefit to both aging adults and those they positively influence through their social engagement in accomplishing ADLs.

A life-span perspective in long-term career planning to better support career work life extension is needed for all cohorts, present and future, regardless of individualdifference characteristics. The "key" is to continually update one's knowledge about an aging workforce to ensure these efforts are effective! Job reactions are a multi-dimensional, complex, and important source of information for both employers and employees of all ages. The issues raised by the present study are not only for older workers, but relate to all workers across the life span. All cohorts will experience "aging" in the workplace, and this cohort by aging dynamic does need to be acknowledged rather than assumed to be universal for all age groups. Further, organizational assessment needs to go beyond the age by job satisfaction relationship to more specific workplace issues, as well as factors of gender role and culture as it affects job reactions. Ultimately, if not better understood, there may be a likely increase in qualified, capable older workers exiting the workforce involuntarily (i.e., "discouraged workers"), and potentially creating "gaps" in job positions that may not be replaceable in full.

\section{REFERENCES}

[1] Barth, M. C., McNaught, W., \& Rizzi, P. (1993). Corporations and the aging workforce. In P. H. Mirvis (ed.), Building the competitive workforce: Investing in human capital for corporate success. New York: Wiley.

[2] Butt, D. S., \& Beiser, M. (1987). Successful aging: A theme for international psychology. Psychology and Aging, 2(1), 87-94. doi:10.1037/08827974.2.1.87

[3] Capowski, G. (1994). Ageism: The new diversity issue. Management Review, 83(10), 10-15.

[4] Carr, D. (2004). Psychological well being across three cohorts: A response to shifting work-family opportunities and expectations? In Brim, 0.
G., Ryff, C. D., \& Kessler, R. C. (Eds), How healthy are we?: A national study of well being at midlife. Chicago, IL: University of Chicago Press.

[5] Farr, J. L., Tesluk, P. E., \& Klein, S. R. (1998). Organizational structure of the workplace and the older worker. In K. W. Schaie \& C. Schooler (eds.), Impact of work on older adults (pp. 143185). New York: Springer.

[6] Fillenbaum, G. G. (1971). On the relation between attitude to work and attitude to retirement. Journal of Gerontology, 26(2), 244-248.

[7] Forteza, J. A., \& Prieto, J. M. (1994). Aging and work behavior. In Triandis, H. C., Dunnette, M. D., \& Hough, L. M. (Eds), Handbook of industrial and organizational psychology. Palo Alto, CA: Consulting Psychologists Press.

[8] Gray, L., \& McGregor, J. (2003). Human resource development and older workers: Stereotypes in New Zealand. Asia Pacific Journal of Human Resources, 41(3), 338-353. doi:10.1177/1038411103041003006

[9] Griffiths, A. (1999). Work design and management: The older worker. Experimental Aging Research, 25(4), 411-420. doi:10.1080/036107399243887

[10] Hedge, J. W., Borman, W. C., \& Lammlein, S. E.(2006). The aging workforce: Realities, myths, and implications for organizations. Washington, DC: APA.

[11] Janiszewski, R. D. (N.D.). Motivational factors that influence baby boomers versus Generation $\mathrm{X}$ : Independent insurance agents. Unpublished dissertation manuscript.

[12] Kidwell, R.E., Jr. (2003). Helping older workers cope with continuous quality improvement. Journal of Management Development, 22(10), 890-905. doi:10.1108/02621710310505485

[13] Kiyonaga, N. B. (2004). Today is the tomorrow you worried about yesterday: Meeting the challenges of a changing workforce. Public Personnel Management, 33(4), 357-361. 
New Age Audit Assessment Approach for Older Workers in a Longevity Economy: Ways to Support Their Positive Health Outcomes and Career Work-life Extension Efforts

[14] Leibold, M., Nohria, N., \& Voelpel, S. C. (2007). Managing the aging workforce: Challenges and solutions. New York: John Wiley \& Sons.

[15] Louhevaara, V., Penttinen, J., \& Tuomi, K. (1999). Work ability and job demands of aging whiteand blue-collar workers in 1981 and 1996. Experimental Aging Research, 25(4), 307-311. doi:10.1080/036107399243751

[16] Lund, T., \& Borg, V. (1999). Work environment and self-rated health as predictors of remaining in work 5 years later among Danish employees 35-59 years of age. Experimental Aging Research, 25(4), 429-434. doi:10.1080/036107399243904

[17] Mutchler, J. E., Burr, J. A., Pienta, A. M., \& Massagli, M. P. (1997). Pathways to labor force exit: Work transitions and work instability. Journal of Gerontology: Social Sciences, 52B, S4-S12.

[18] Noonan, A.E. (2005). "At this point now": Older workers' reflections on their current employment experiences. International Journal of Aging \& Human Development, 61(3), 211-241. doi:10.2190/38CX-C90V-0K37-VLJA

[19] Oromaner, M. (2006). Thriving on an aging workforce: Strategies for organizational and systemic change. Personnel Psychology, 59(1), 261-264.

[20] Palmore, E. B. (1969). Physical, mental, and social factors in predicting longevity. Gerontologist, 9, 103-108.
[21] Rhodes, S. R. (1983). Age-related differences in work attitudes and behavior: A review and conceptual analysis. Psychological Bulletin, 93, 328-367. doi:10.1037/0033-2909.93.2.328

[22] Seitsamo, J., \& Martikainen, R. (1999). Changes in capability in a sample of Finnish aging workers. Experimental Aging Research, 25(4), 345-352. doi:10.1080/036107399243797

[23] Sterns, H. L., \& Doverspike, D. (1989). Aging and the training and learning process. In Goldstein, I. L. (Ed.), Training and development in organizations. San Francisco, CA: Jossey-Bass.

[24] Thoresen, C. J., Kaplan, S. A., Barsky, A. P., Warren, C. R., \& de Chermont, K. (2006). The affective underpinnings of job perceptions and attitudes: A meta-analytic review. Psychological Bulletin, 129(6), 914-945. doi:10.1037/00332909.129.6.914

[25] U.S. Census Bureau (2000). Population projections of the United States by age, sex, race, Hispanic origin, and nativity. Washington, DC: U.S. Government Printing Office.

[26] U.S. Census Bureau (2004). U.S. interim projections by age, sex, race, and Hispanic origin. Washington, DC: U.S. Government Printing Office.

[27] Wright, J. (2006). Crisis and opportunity: Coaching older workers in the workplace. Work: Journal of Prevention, Assessment \& Rehabilitation, 26(1), 93-96.

Citation: Lisa Hollis-Sawyer, Ph.D. New Age Audit Assessment Approach for Older Workers in a Longevity Economy: Ways to Support Their Positive Health Outcomes and Career Work-life Extension Efforts. Open Journal of Geriatrics. 2018; 1(1): 73-79.

Copyright: (C) 2018 Lisa Hollis-Sawyer, Ph.D. This is an open access article distributed under the Creative Commons Attribution License, which permits unrestricted use, distribution, and reproduction in any medium, provided the original work is properly cited. 